\title{
www.SpringerMedizin.de
}

\section{Das Internet der Ärzte}

\section{Sie möchten medizinisch auf dem Laufenden bleiben? \\ Bei Experten Ihres Fachgebiets Rat suchen, in spannenden Kasuistiken stöbern oder CME-Punkte ergattern? Dann sind Sie auf SpringerMedizin.de, dem neuen Fachportal für Ärzte, goldrichtig. Denn dort erwartet Sie eine Fülle von nützlichen Informationen - maßgeschneidert auf Ihr Fachgebiet.}

- SpringerMedizin.de ist ein Fachportal für Ärzte. Deshalb müssen diejenigen, die noch nicht bei SpringerMedizin-Login registriert sind, zunächst eine notwendige Hürde nehmen: Alle medizinischen Inhalte auf SpringerMedizin.de sind passwortgeschützt. Die kostenlose Registrierung (wie es geht, siehe S. 19) ist aber schnell erledigt und bietet einen großen Vorteil: Gibt man sich bei der Registrierung mit seinem Fachgebiet zu erkennen, erhält man automatisch als personalisierte Startseite das passende Fachportal - z.B. das für Allgemeinmediziner - angezeigt.

Diese Startseite kann man nun weiter anpassen: Die grauen Rubrikenkästen Anpassung in einem Film erklärt. (sog. Portlets) lassen sich verschieben, umgruppieren oder auch wegklicken. Über den Knopf „Mehr Inhalte hinzufügen" kann man weitere Rubriken auswählen und auf der Startseite anzeigen lassen. Wenn die Konfiguration abgespeichert wird, erscheint sie beim nächsten Log-in genau so wieder. Über den orangenen Button „Guided Tour“ werden alle Möglichkeiten der individuellen

\section{Das Wichtigste auf den ersten Blick}

Es lohnt sich, mehrmals am Tag mit SpringerMedizin.de online zu gehen. Unsere Aufmacherposition im oberen

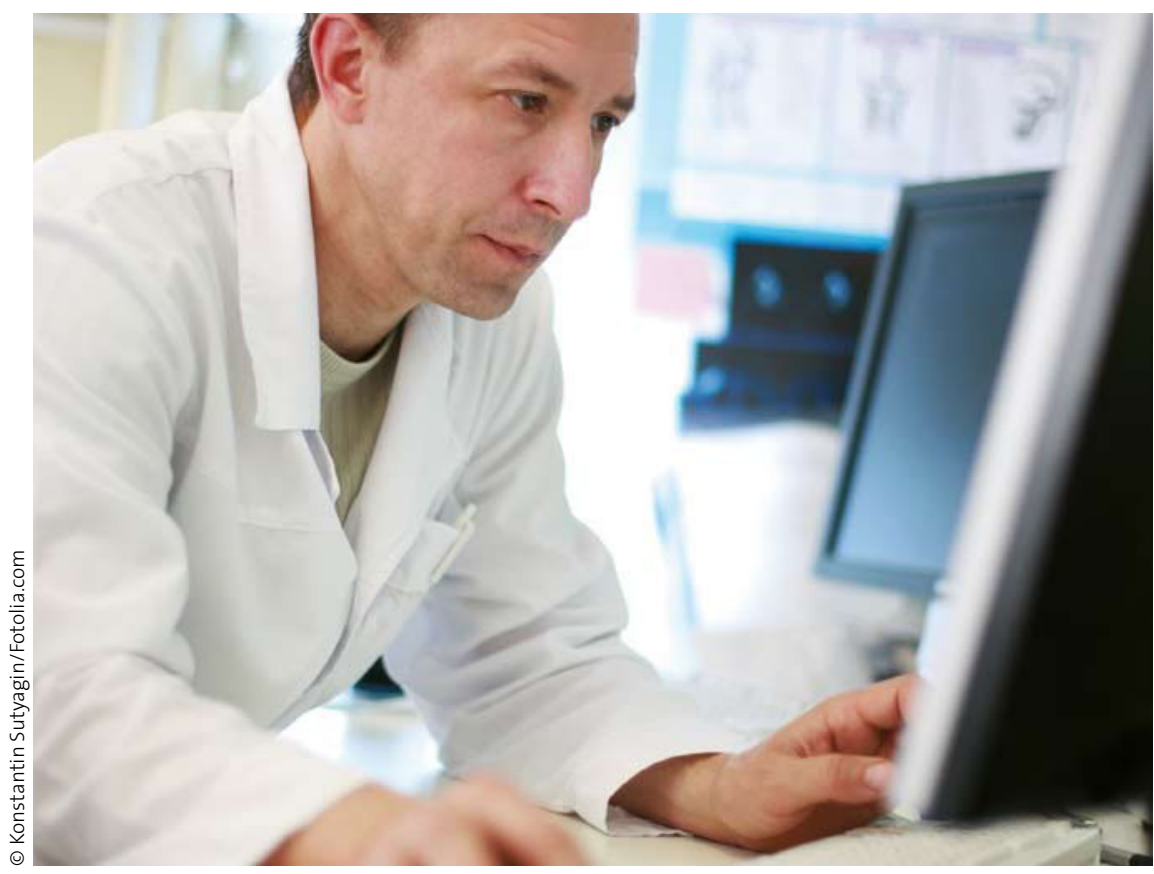

Die ganze Welt der Medizin ist nur wenige Klicks entfernt. www.SpringerMedizin.de ist das Fachportal für Ärzte in Deutschland. blauen Bereich bietet Ihnen täglich neue interessante Themen aus Medizin und Gesundheitspolitik. Weitere News aus der Hauptstadt und Informationen, was sich in den einzelnen Bundesländern und KVen tut, stehen im Portlet "Gesundheitspolitik“ bereit.

Täglich neue Meldungen zu medizinischen Themen finden Sie unter Medizin kompakt. Kurz und bündig geben Ihnen diese Meldungen einen schnellen Überblick, was sich in Ihrem Fachgebiet alles tut. Möchten Sie daneben auch News aus anderen Fachgebieten lesen - kein Problem, konfigurieren Sie Ihr Portlet ganz nach Wunsch.

\section{Fortbildung satt}

Wer tiefer in die Medizin eintauchen möchte, wird unter dem Navigationspunkt „Fortbildung“ fündig. Dort stehen interessante Übersichtsarbeiten, spannende Kasuistiken und CME-Fortbildungen zur Verfügung. Und unser aktueller Kongresskalender, der Ihnen genau sagt, wann und wo für Sie wichtige Veranstaltungen und Kongresse stattfinden.

\section{Stöbern lohnt sich!}

Sie möchten Deutschlands beliebteste Leiche kennenlernen? Die Diagnose der Mona Lisa wissen oder medizynische Anekdoten lesen? Dann sollten Sie das Portlet „Vermischtes“ ansteuern. Wer gerne in Zeitschriften-Archiven stöbert, wird unter "Zeitschriften “ fündig. Dort stehen für Abonnenten die Inhalte von über 70 renommierten Titeln bis in die 1990er-Jahre bereit.

Diese Beispiele sind nur ein Bruchteil dessen, was www.SpringerMedizin. de zu bieten hat. Steuern Sie das Internet der Ärzte an und lassen Sie sich überraschen! Es lohnt sich.

\footnotetext{
- Dr. MED. SONJA KeMPINSKI,

Chefredakteurin SpringerMedizin.de
} 